\title{
Immunohistochemical study on neuropilin 1 (NRP1) immunoexpression in oral squamous cell carcinoma
}

\author{
Olga Stasikowska-Kanicka1, Malgorzata Wagrowska-Danilewicz ${ }^{1}$, Marian Danilewicz ${ }^{2}$
}

${ }^{1}$ Department of Nephropathology, Medical University of Lodz, Lodz, Poland
${ }^{2}$ Department of Pathomorphology, Medical University of Lodz, Lodz, Poland

\begin{abstract}
Introduction. Neuropilins (NRPs) are multifunctional glycoproteins that play an important role in angiogenesis and cancer progression. The aim of the study was to examine the immunoexpression of neuropilin 1 (NRP1), the number of NRP1+ infiltrating cells and CD163+ macrophages, and density of microvessels (MVD) in oral squamous cell carcinoma (OSCC).

Material and methods. The study was performed on 45 OSCC patients with metastases (OSCCM+), 51 patients without metastases (OSCCM-) and 17 control cases. The microvessels were identified by the presence of CD31 and the expression of the studied proteins was assessed by immunohistochemistry.

Results. The immunoexpression of NRP1, the mean numbers of NRP1+, CD163+ infiltrating cells, and MVD were significantly increased in OSCCM+ patients in comparison to OSCCM-, and control groups. Moreover, in OSCCM- patients all these parameters were also significantly increased in comparison to controls. In OSCCM+ and OSCCM- groups, there were positive correlations between the immunoexpression of NRP1 and MVD $(\mathrm{r}=0.41, \mathrm{p}<0.006 ; \mathrm{r}=0.51, \mathrm{p}<0.001$, respectively), and between the number of NRP1+ infiltrating cells and CD163+ macrophages ( $\mathrm{r}=0.56, \mathrm{p}<0.001, \mathrm{r}=0.49, \mathrm{p}<0.001$, respectively).

Conclusions. The present study revealed overexpression of NRP1 in OSCC, especially in OSCC patients with metastasis, suggesting that NRP1 could potentially contribute to metastasis of oral cancer. The correlation between the number of NRP1+ infiltrating cells and CD163+ macrophages suggests that NRP1+ infiltrating macrophages are present in tumor microenvironment and may play a role in the progressions of oral cancer. (Folia Histochemica et Cytobiologica 2018, Vol. 56, No. 2, 98-105)
\end{abstract}

Key words: neuropilin 1; macrophages; angiogenesis; oral cancer; metastasis; IHC

\section{Introduction}

Oral squamous cell carcinoma (OSCC) is the most commonly identified cancer of the oral cavity and the head and neck region. OSCC is a major cause of morbidity and mortality worldwide, accounting for at least $90 \%$ of all oral malignancies [1-3].

Tumor angiogenesis is a crucial process during carcinogenesis that modulates tumor growth and metastasis. Tumor growth beyond the volume of 1 to $2 \mathrm{~mm}^{3}$ is angiogenesis dependent [4]. Therefore,

\footnotetext{
Correspondence address: O. Stasikowska-Kanicka, $\mathrm{PhD}$ Department of Nephropathology, Medical University of Lodz Czechoslowacka 8/10, 92-216 Lodz, Poland tel.|fax +48 426790191

e-mail: olga.stasikowska@umed.lodz.pl
}

understanding the mechanisms that control tumor neovascularization may lead to the development of new options for cancer treatment. Neuropilins (NRP1 and NRP2) are multifunctional glycoproteins that play an important role in angiogenesis and cancer progression [5-7]. NRP1 is a single transmembrane glycoprotein with a molecular weight of approximately 130-140 kDa. NRP1 consists of a large extracellular domain, and short transmembrane and cytoplasmic domains [8]. NRP1 is expressed on endothelial cells, dendritic cells, regulatory T cells, as well as on malignant tumor cells [8-11]. NRP1 overexpression on tumor cells influences neovascularization by the binding and release of angiogenic factors (VEGF, vascular endothelial growth factor, PIGF, placenta growth factor, HGF, hepatocyte growth factor) [12]. An increased level of these ligands within the local tumor microenviron- 
Table 1. Clinicopathological characteristics of patients with oral squamous cell carcinomas (OSCC) with metastases OSCCM+, and without metastases OSCCM-

\begin{tabular}{|c|c|c|c|c|}
\hline \multirow[t]{3}{*}{ Clinical variables } & \multicolumn{2}{|c|}{$\begin{array}{c}\text { OSCCM+ } \\
\text { n }(\%)\end{array}$} & \multicolumn{2}{|c|}{$\begin{array}{c}\text { OSCCM- } \\
\text { n (\%) }\end{array}$} \\
\hline & Men & Women & Men & Women \\
\hline & $26(57.8)$ & $19(42.2)$ & $30(58.8)$ & $21(41.2)$ \\
\hline \multicolumn{5}{|l|}{ Age } \\
\hline$<60$ (Median 52 ys, range 28-59) & $10(22.2)$ & $8(17.8)$ & $12(23.5)$ & $10(19.6)$ \\
\hline$\geq 60$ (Median 72 ys, range $60-84$ ) & $16(35.6)$ & $11(24.4)$ & $18(35.3)$ & $11(21.6)$ \\
\hline \multicolumn{5}{|l|}{ Histopathological grade } \\
\hline G1 & $0(0)$ & $0(0)$ & $1(2)$ & $3(5.9)$ \\
\hline G2 & $22(48.9)$ & $17(37.8)$ & $28(47)$ & $18(43.1)$ \\
\hline G3 & $4(8.9)$ & $2(4.4)$ & $1(2)$ & $0(0)$ \\
\hline
\end{tabular}

ment attracts and induces sprouting of endothelial cells in stromal compartment $[5,6]$.

NRP1 overexpression was detected in various human cancers including colon, pancreatic, tongue carcinoma and astrocytic tumors [13-16]. Previous studies have shown that NRP1 overexpression is positively associated with metastatic potential, advanced stage, and clinical grade in human carcinoma including tumors of gastrointestinal tract [17] and oral cancer [18].

Although the immunoexpression of NRP1 in various types of tumors have been extensively characterized, the precise role of the immunoexpression of NRP1, NRP1 + infiltrating cells and their associations with microvessels density are not clear. Therefore, the aim of our study was to evaluate the immunoexpression of NRP1, the number of NRP1+, CD163+ infiltrating cells and microvessels density (CD31+ vessels) in patients with oral squamous cell carcinomas with metastases (OSCCM+), and without metastases (OSCCM-). Another purpose was to find a possible association between the immunoexpression of NRP1, the presence of macrophages and microvessel density.

\section{Material and methods}

Patients. The Medical University of Lodz review board approved the methods of the present retrospective study. The authors have complied with the World Medical Association Declaration of Helsinki regarding ethical conduct of research involving human subjects. The study was conducted under the assumption that research findings would be kept anonymous.

Ninety-six patients with OSCC, and seventeen controls (normal mucosa of oral cavity), were sourced from archival tissue blocks of the Department of Pathomorphology, Medical University of Lodz, Poland. Normal oral mucosa from the floor of the mouth (non-cancer-affected patients) originated from Department of Plastic and Reconstructive Surgery, Medical University of Lodz. All tissue sections taken from postoperative material were routinely fixed in formalin, processed, embedded in paraffin, and stained with hematoxylin and eosin. Histopathological diagnoses were established according to the current standards [19]. The main criterion used for the selection of cases was an anatomical placement of the lesion (the floor of the mouth). All the studied cases of OSCC were divided into two groups: OSCCM(patients without metastases, $\mathrm{n}=51$ ), and OSCCM+ (patients with metastases to regional lymph nodes or/and with distant metastases, $n=45$ ). Cases of OSCC were graded according to the WHO classification [19]. The average age of OSCCM- patients was $57.54 \pm 9.31$ years (mean $\pm \mathrm{SD}$, age range 28-75 years), of OSCCM+ patients was $58.39 \pm 10.36$ (age range 40-84), and of control patients $43.15 \pm 18.22$ (age range 15-74). Clinicopathological characteristics of patients with OSCCM+ and OSCCM- are presented in Table 1.

Immunohistochemistry. Immunohistochemical staining was carried out according to a standard method. 3- $\mu \mathrm{m}$-thick tissue sections were deparaffinized in xylene and rehydrated through a graded alcohol series. Heating in a microwave oven in a solution of TRS (Target Retrieval Solution, $\mathrm{pH}$ 9.0, Dako, Glostrup, Denmark), for 30 min was used for antigen retrieval. Endogenous peroxidases were quenched with $0,3 \%$ hydrogen peroxide in methanol for $30 \mathrm{~min}$. The sections were washed with TBS and incubated with monoclonal mouse primary antibodies against: CD163 (Abcam, Cambridge, UK; clone 10D6, ready-to-use), CD31 (Dako, clone JC70A, dilution 1:50), and rabbit polyclonal antibody against NRP1 (Thermo Scientific, Rockford, PA,USA, PA 5-26079, dilution 1:200). After washing, an adequate EnVision-HRP detection system (Dako) was used. 3,3'-diaminobenzidine was used as the chromogen. After counterstaining with Mayer's hematoxylin, the slides were washed, dehydrated, 
cleared in xylene and coverslipped. The negative controls underwent the same procedure, with the primary antibodies replaced by antibody diluent.

In each specimen distribution and cytoplasmic staining intensity of NRP1 in epithelial cells were recorded semiquantitatively by two independent observers in 7-10 (depending on the specimen size) adjacent high power fields and graded from 0 (staining not detectable), 1 (weak immunostaining), 2 (moderate immunostaining intensity) and 3 (strong staining). The mean grade was calculated by averaging grades assigned by the two observers and approximating the arithmetical mean to the nearest unity.

\section{Morphometry \\ Morphometric analysis of NRP1 + and CD163+ infiltrating cells. NRP1+, and CD163+ infiltrating cells were evaluated using a computer image analysis system consisting of a PC equipped with a Pentagram graphic tablet, Indeo Fast card (frame grabber, true-color, real-time), produced by Indeo (Taiwan), and a color TV camera (Panasonic, Tokyo, Japan) coupled with a microscope (Carl Zeiss, Jena, Germany). This system was programmed (MultiScan 18.03 software, produced by Computer Scanning Systems, Lodz, Poland) to calculate the number of objects (semiautomatic function). \\ The number of NRP1+ and CD163+ infiltrating cells was estimated by counting all positive cells in 7-10 high power monitor fields (HPF, $0.029 \mathrm{~mm} 2$ each), marking immunopositive cells (semiautomatic function).}

Analysis of microvessel density (MVD). Microvessel density (CD31+ vessels) was evaluated using the same computer image analysis system as described above. CD31 immunostaining was evaluated in the vessels only (not in the individual cells), in the most vascularized areas [20]. The results were presented as the mean number of CD31 immunopositive vessels with visible lumina per HPF.

Statistical analysis. Differences between groups were tested using one-way ANOVA with post-hoc Tukey test. The Kruskal-Wallis test with post-hoc Dunn's test was used where appropriate. Correlation coefficients were calculated using Spearman's method. Results were considered statistically significant if $\mathrm{p}<0.05$.

\section{Results}

The immunoexpression of NRP1 was localized in the epithelial cells, cancer cells, vascular endothelial cells, and in the infiltrating stromal cells. Our study revealed that the majority of the NRP1 was localized in the cytoplasm and cell membrane, although extracellular immunoexpression was also noted.

The semiquantitative data of the immunoexpression of NRP1, and the mean number of NRP1+,
CD163 + cells and number of CD31+ vessels are shown in Table 2.

The immunoexpression of NRP1 in OSCCM+ group (Fig. 1A) was significantly increased in comparison to OSCCM-(Fig. 1B), and control groups (Fig. 1C). Moreover, in OSCCM- group immunoexpression of NRP1 was significantly increased in comparison to controls. In both group of OSCCs, NRP1+ cells were noted both within tumor and tumor adjacent tissue. Significantly increased number of infiltrating NRP1 + cells was found in OSCCM+ (Fig. 1 D), and OSCCM- (Fig. $1 \mathrm{E}$ ) group compared to control samples (Fig. 1F). In OSCCM+ group, the number of NRP1+ cells was significantly increased in comparison to OSCCM- group.

In OSCCs, CD163+ macrophages were detected in cancer stroma and in the peritumor tissues. The mean number of CD163+ cells was significantly increased in OSCCM+ group (Fig. 2A) in comparison to OSCCM- (Fig. 2B), and control group (Fig. 2C). Moreover, significantly increased number of CD163+ cells were found in OSCCM- compared to controls.

MVD was significantly increased in OSCCM+ group (Fig. 2D) in comparison to OSCCM- (Fig. 2E), and control group (Fig. 2F). We found also significantly increased MVD in OSCCM- compared to control group.

In OSCCM+ and OSCCM- groups there were positive significant correlations between the immunoexpression of NRP1 and MVD ( $\mathrm{r}=0.41, \mathrm{p}<0.006$; $\mathrm{r}=0.51, \mathrm{p}<0.001$ respectively). Moreover, in both OSCCM- and OSCCM+ groups, there were significantly positive correlations between the mean number of NRP1 + cells and the number of CD163+ macrophages $(\mathrm{r}=0.56, \mathrm{p}<0.001 ; \mathrm{r}=0.49, \mathrm{p}<0.001$ respectively) (Table 3 ).

In the control group all these correlations were weak and not statistically significant (data not shown).

\section{Discussion}

Many studies documented that the increased expression of NRP1 in the tumor cells is a poor prognostic factor in malignant neoplasm since the expression of NRP1 was correlated with advanced tumor stage and/or progression in many cancers [17, 21-24]. Our study on oral squamous cell cancer patients with or without metastases supports previous findings. In our study, NRP1 was poorly expressed in normal oral epithelium but was increased on cancer cells. Moreover, we demonstrated that NRP1 immunoexpression was significantly higher in OSCC with metastasis than in the group of cancers without metastasis. Similar results were showed by Lu et al. who 

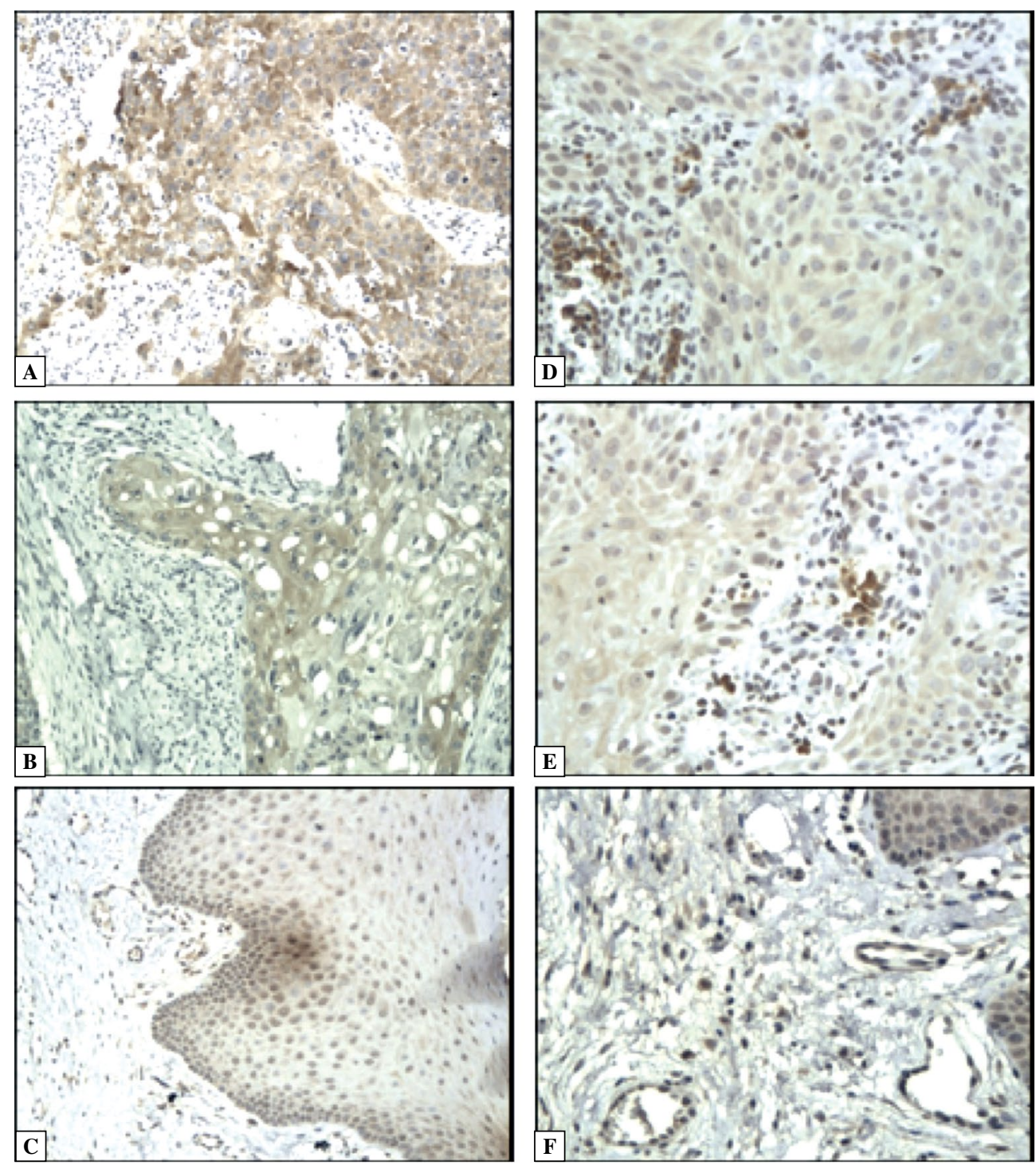

Figure 1. Immunoexpression of neuropilin 1 (NRP1) in oral squamous cell carcinomas (OSCC). A. OSCC patient with metastases. B. OSCC without metastases. C. control patient. (D-F) Immunoexpression of NRP1 in the infiltrating cells of the tumor stroma: (D) OSCC with metastases, (E) OSCC without metastases, (F) control. The immunohistochemical staining was performed as described in Methods. Magnification $200 \times$.

Table 2. The immunoreactivity of neuropilin 1 (NRP1), and the number of NRP1+, CD163+ infiltrating cells and the microvessels density (MVD) in oral squamous cell carcinomas with metastasis OSCCM + , in oral squamous cell carcinomas without metastasis OSCCM- and control subjects

\begin{tabular}{|l|c|c|c|c|}
\hline Groups & $\begin{array}{c}\text { NRP1 immunoreactivity } \\
\text { (mean score) }\end{array}$ & $\begin{array}{c}\text { No. of NRP1+ } \\
\text { cells/HPF }\end{array}$ & $\begin{array}{c}\text { No. of CD163+ } \\
\text { cells/HPF }\end{array}$ & $\begin{array}{c}\text { MVD (No. of CD31+ } \\
\text { vessels/HPF }\end{array}$ \\
\hline OSCCM+ $(\mathrm{n}=45)$ & $2.34 \pm 1.82$ & $12.3 \pm 5.6$ & $75.6 \pm 36.2$ & $69.5 \pm 30.8$ \\
\hline OSCCM- $(\mathrm{n}=51)$ & $1.46 \pm 1.16$ & $9.6 \pm 4.9$ & $47.6 \pm 26.5$ & $43.2 \pm 17.4$ \\
\hline Controls $(\mathrm{n}=17)$ & $0.54 \pm 0.32$ & $5.5 \pm 2.1$ & $28.3 \pm 22.2$ & $29.3 \pm 16.5$ \\
\hline OSCCM- $v$ s. OSCCM+ & $\mathrm{p}<0.006$ & $\mathrm{p}<0.02$ & $\mathrm{p}<0.001$ & $\mathrm{p}<0.001$ \\
\hline OSCCM+ vs. control & $\mathrm{p}<0.001$ & $\mathrm{p}<0.02$ & $\mathrm{p}<0.001$ & $\mathrm{p}<0.001$ \\
\hline OSCCM- $v$ s. control & $\mathrm{p}<0.003$ & $\mathrm{p}<0.002$ & $\mathrm{p}<0.009$ & $\mathrm{p}<0.006$ \\
\hline
\end{tabular}

Data are presented as a mean $\pm \mathrm{SD}$. Abbreviations: NRP1 - neuropilin 1; HPF — high power field; NS — not significant. 

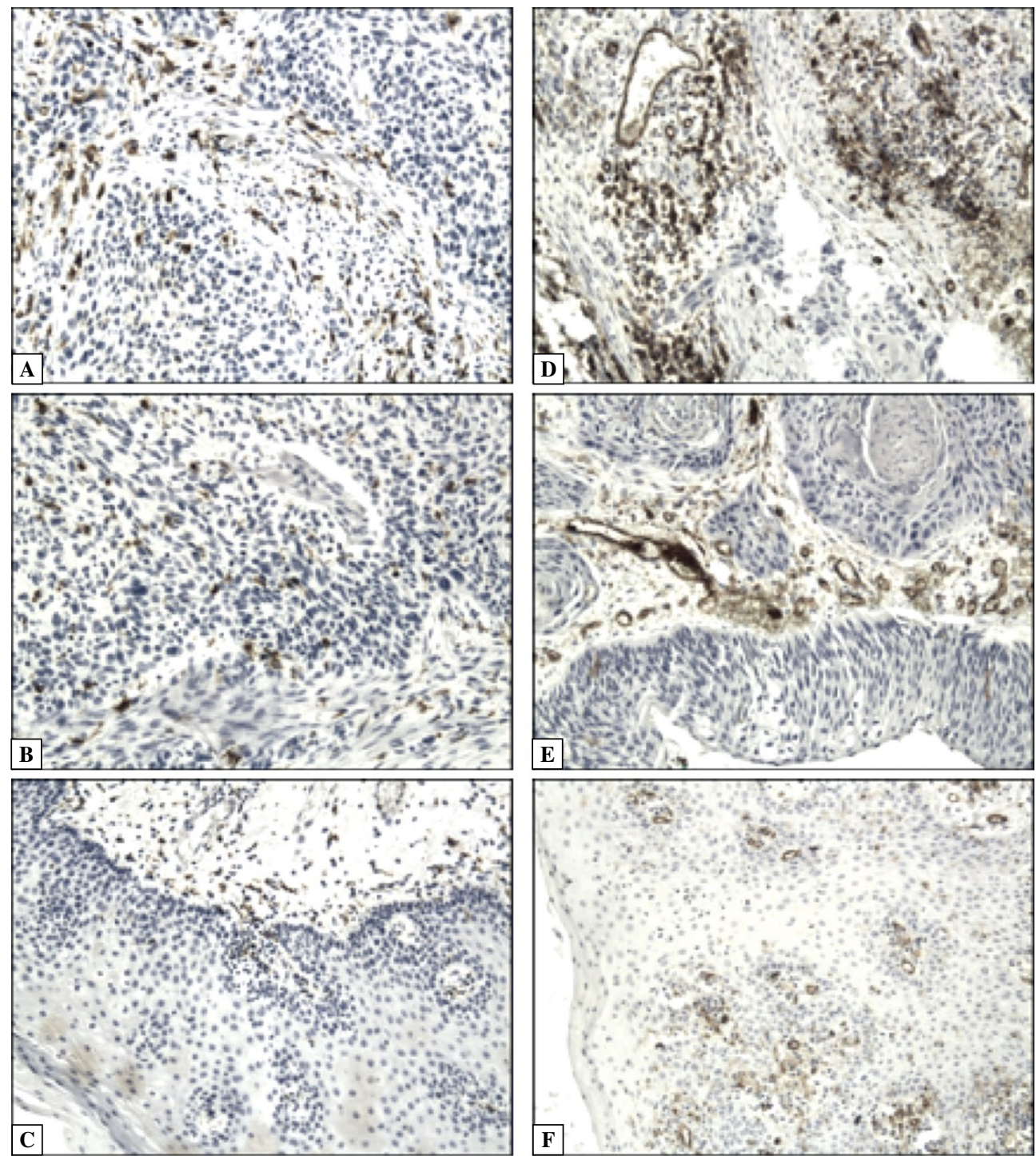

Figure 2. Immunoexpression of CD163 in cells and CD31 in vessels of oral cancer stroma. (A-C): CD163+ immunoreactivity on the infiltrating cells of the tumor stroma: A. OSCC with metastases, B. OSCC without metastases, C. in control. (D-F) CD31+ immunoreactivity in vessels of oral cancer stroma: D. OSCC with metastases, E. OSCC without metastases, F. control. Abbreviations as in the description of Figure 1. The immunohistochemical staining was performed as described in Methods. Magnification $200 \times$.

Table 3. The correlations between the immunoexpression of neuropilin 1 (NRP1) on cancer cells, NRP1+ tumor-infiltrating cells and CD163+ macrophages as well as microvessels density (MVD) in oral squamous cell carcinomas with metastasis OSCCM+, and oral squamous cell carcinomas without metastasis OSCCM-

\begin{tabular}{|l|c|c|}
\hline Correlation between & OSCCM+ $(\mathbf{n}=\mathbf{4 5})$ & OSCCM- $(\mathbf{n}=\mathbf{5 1})$ \\
\hline NRP1+ infiltrating cells $v s$. CD163+ cells & $\mathrm{r}=0.56$, & $\mathrm{r}=0.49$, \\
& $\mathrm{p}<0.001$ & $\mathrm{p}<0.001$ \\
\hline NRP1+ infiltrating cells $v s$. MVD & $\mathrm{r}=0.29$, & $\mathrm{r}=0.21$, \\
& $\mathrm{p}=0.053$ & $\mathrm{p}=0.139$ \\
\hline NRP1 immunoreactivity $v s$. MVD & $\mathrm{r}=0.41$, & $\mathrm{r}=0.51$, \\
& $\mathrm{p}<0.006$ & $\mathrm{p}<0.001$ \\
\hline
\end{tabular}


analyzed the correlations between NRP1 expression and the clinical stage of malignant melanoma [25]. In ovarian cancer, NRP1 was also positively correlated with the degree of the FIGO stage [26]. Interestingly, in cutaneous squamous cell carcinoma, which is less invasive and rarely metastatic, Shahrabi-Farahani et al. demonstrated that the NRP1 expression did not correlate with stage and cancer progression but was associated with the degree of differentiation only [27]. Our results seem to be also in agreement with reports of experimental findings. Beck et al. reported that mice lacking Nrp1 in epithelial cells did not develop skin tumors after carcinogen treatment, whereas wild-type mice expressing Nrp1 developed tumors [28]. All these findings may suggest that NRP1 is an important factor that participates in the regulation of carcinogenesis and the cell migration. It was found that overexpression of NRP1 in cancer cells results in enhanced tumor size in vivo, although NRP1 does not directly increase proliferation of colon cancer [13] or rat prostate carcinoma AT2.1 [29] cells in vitro. These findings suggest that the tumor microenvironment can significantly modify NRP1 function in tumorigenesis.

Neuropilin 1 is a VEGF and semaphorin receptor and it was shown that NRPs play an important role in angiogenesis. The essential role of NRP1 in angiogenesis was established in NRP1-null mice, which show high embryonic mortality due to serious defects in blood vessel formation [30,31]. NRP1 was found to be overexpressed and positively associated with angiogenesis in several types of human cancers. Kawakami et al. revealed that NRP1 expression is significantly correlated with increased vascularity and poor prognosis in non-small cell lung carcinoma [32]. Ben et al. found that high expression of NRP1 was associated with the neovascularization in the pancreatic ductal adenocarcinoma [33]. The significant correlation between the NRP1 overexpression in oral cancer and the process of angiogenesis defined as the increase in MVD stress the importance of NRP1 both in primary tumors and in the metastases.

It was reported that NRP1 is expressed not only on endothelial and cancer cells but also on macrophages, and other cell types present in the tumor microenvironment [10, 11, 34, 35]. Our finding that in oral squamous cell carcinoma the number of infiltrating NRP1+ cells correlated with the number of CD163+ infiltrating cells, suggests that the part of the NRP1+ cells represented M2 macrophages. Several studies have documented that immunosuppressive CD163+ M2 macrophages are the predominant population of TAMs in tumor microenvironment, associated with tumor development including processes of angiogenesis and metastasis [36-38]. Recent reports have suggested that NRP1 could be a pivotal molecule for macrophage regulation and that NRP1+ macrophages might play an important role in tumor microenvironments. Ji et al. showed in an experimental study on mice that the majority of macrophages expressing NRP1 in tumor microenvironment possess M2 phenotype [39]. Casazza et al. studying several tumor mouse models found that the NRP1+ macrophages are specifically increased in hypoxic areas, resulting in the accumulation of protumoral macrophages that led to tumor progression [40]. We found that in patients with higher CD163+ cells infiltration and the increased number of NRP1+ cells, MVD was also increased; however, there was no correlation between the number of NRP1+ cells and MVD. Our data may suggest a protumorigenic role for NRP1+ cell, but further studies are needed to explore the precise role of NRP1+ macrophages in the oral tumorigenesis.

In conclusion, the present study revealed overexpression of NRP1 in oral squamous cell cancers, especially in patients with metastasis what suggests that NRP1 could potentially contribute to metastasis of oral cancer. Moreover, our findings support the presence of NRP1+ infiltrating macrophages in tumor microenvironment. To the best of our knowledge, this is the first study considering the MVD in OSCC in the context of tumor infiltration by NRP1+ immune cells. Further investigations are is required to determine the underlying mechanisms by which NRP1+ immune cells participate in oral tumorigenesis.

\section{Acknowledgment}

This work was supported by grant of Medical University of Lodz 503/6-038-01/503-61-002.

\section{Conflict of interest}

The authors declare that there is no conflict of interest regarding the publication of this paper.

\section{References}

1. Ferlay J, Soerjomataram I, Ervik M, et al. GLOBOCAN 2012 v1.0, Cancer Incidence and Mortality Worldwide: IARC CancerBase No. 11 [Internet]. Lyon, France: International Agency for Research on Cancer; 2013. http://globocan.iarc. fr, accessed on 03/09/2016.

2. Forastiere AA, Ang K, Brizel D, et al. National Comprehensive Cancer Network. Head and neck cancers. J Natl Compr Canc Netw. 2005; 3(3): 316-391, indexed in Pubmed: 16002004.

3. Hunter KD, Parkinson EK, Harrison PR. Profiling early head and neck cancer. Nat Rev Cancer. 2005; 5(2): 127-135, doi: 10.1038/nrc1549, indexed in Pubmed: 15685196.

4. Folkman J. Is angiogenesis an organizing principle in biology and medicine? J Pediatr Surg. 2007; 42(1): 1-11, doi: 10.1016/j. jpedsurg.2006.09.048, indexed in Pubmed: 17208533. 
5. Wang L, Zeng H, Wang P, et al. Neuropilin-1-mediated vascular permeability factor/vascular endothelial growth factor-dependent endothelial cell migration. J Biol Chem. 2003; 278(49): 48848-48860, doi: 10.1074/jbc.M310047200, indexed in Pubmed: 14514674.

6. Wang L, Mukhopadhyay D, Xu X. C terminus of RGS-GAIP-interacting protein conveys neuropilin-1-mediated signaling during angiogenesis. FASEB J. 2006; 20(9): 1513-1515, doi: 10.1096/fj.05-5504fje, indexed in Pubmed: 16754745.

7. Prud'homme GJ, Glinka Y. Neuropilins are multifunctional coreceptors involved in tumor initiation, growth, metastasis and immunity. Oncotarget. 2012; 3(9): 921-939, doi: 10.18632/ /oncotarget.626, indexed in Pubmed: 22948112.

8. Pellet-Many C, Frankel P, Jia H, et al. Neuropilins: structure, function and role in disease. Biochem J. 2008; 411(2): 211 -226, doi: 10.1042/BJ20071639, indexed in Pubmed: 18363553.

9. Uniewicz KA, Fernig DG. Neuropilins: a versatile partner of extracellular molecules that regulate development and disease. Front Biosci. 2008; 13: 4339-4360, indexed in Pubmed: 18508514.

10. Shimizu A, Zankov DP, Kurokawa-Seo M, et al. Vascular Endothelial Growth Factor-A Exerts Diverse Cellular Effects via Small G Proteins, Rho and Rap. Int J Mol Sci. 2018; 19(4), doi: 10.3390/ijms19041203, indexed in Pubmed: 29659486.

11. Bruder D, Probst-Kepper M, Westendorf AM, et al. Neuropilin-1: a surface marker of regulatory T cells. Eur J Immunol. 2004; 34(3): 623-630, doi: 10.1002/eji.200324799, indexed in Pubmed: 14991591

12. Plein A, Fantin A, Ruhrberg C. Neuropilin regulation of angiogenesis, arteriogenesis, and vascular permeability. Microcirculation. 2014; 21(4):315-323, doi: 10.1111/micc.12124, indexed in Pubmed: 24521511.

13. Parikh AA, Fan F, Liu WB, et al. Neuropilin-1 in human colon cancer: expression, regulation, and role in induction of angiogenesis. Am J Pathol. 2004; 164(6): 2139-2151, doi: 10.1016/ /S0002-9440(10)63772-8, indexed in Pubmed: 15161648.

14. Zhou R, Curry JM, Roy LD, et al. A novel association of neuropilin-1 and MUC1 in pancreatic ductal adenocarcinoma: role in induction of VEGF signaling and angiogenesis. Oncogene. 2016; 35(43): 5608-5618, doi: 10.1038/onc.2015.516, indexed in Pubmed: 26804176.

15. Broholm H, Laursen $\mathrm{H}$. Vascular endothelial growth factor (VEGF) receptor neuropilin-1's distribution in astrocytic tumors. APMIS. 2004; 112(4-5): 257-263, doi: 10.1111/j.16000463.2004.apm11204-0505.x, indexed in Pubmed: 15233640.

16. Song X, Zhang W, Zhang Y, et al. Expression of semaphorin $3 \mathrm{~A}$ and neuropilin 1 with clinicopathological features and survival in human tongue cancer. Med Oral Patol Oral Cir Bucal. 2012; 17(6): e962-e968, indexed in Pubmed: 22926477.

17. Hansel DE, Wilentz RE, Yeo CJ, et al. Expression of neuropilin-1 in high-grade dysplasia, invasive cancer, and metastases of the human gastrointestinal tract. Am J Surg Pathol. 2004; 28(3): 347-356, indexed in Pubmed: 15104297.

18. Wu YY, Chen YL, Jao YC, et al. miR-320 regulates tumor angiogenesis driven by vascular endothelial cells in oral cancer by silencing neuropilin 1 . Angiogenesis. 2014; 17(1): 247-260, doi: 10.1007/s10456-013-9394-1, indexed in $\mathrm{Pu}-$ bmed: 24114198.

19. Barnes L, Everson JW, Reichart P, et al. World Health Organization Classification of Tumours. Pathology and Genetics Head and Neck Tumours. IARC Press Lyon. ; 2005: 168-176.

20. Vermeulen PB, Gasparini G, Fox SB, et al. Second international consensus on the methodology and criteria of evaluation of angiogenesis quantification in solid human tumours.
Eur J Cancer. 2002; 38(12): 1564-1579, indexed in Pubmed: 12142044.

21. Cheng W, Fu D, Wei ZF, et al. NRP-1 expression in bladder cancer and its implications for tumor progression. Tumour Biol. 2014; 35(6): 6089-6094, doi: 10.1007/s13277-014-1806-3, indexed in Pubmed: 24627131.

22. Matkar PN, Singh KK, Rudenko D, et al. Novel regulatory role of neuropilin-1 in endothelial-to-mesenchymal transition and fibrosis in pancreatic ductal adenocarcinoma. Oncotarget. 2016; 7(43): 69489-69506, doi: 10.18632/oncotarget.11060, indexed in Pubmed: 27542226.

23. Shahrabi-Farahani S, Gallottini M, Martins F, et al. Neuropilin 1 Receptor Is Up-Regulated in Dysplastic Epithelium and Oral Squamous Cell Carcinoma. Am J Pathol. 2016; 186(4): 1055-1064, doi: 10.1016/j.ajpath.2015.11.021, indexed in Pubmed: 26877262

24. Chu W, Song X, Yang X, et al. Neuropilin-1 promotes epithelial-to-mesenchymal transition by stimulating nuclear factor-kappa B and is associated with poor prognosis in human oral squamous cell carcinoma. PLoS One. 2014; 9(7): e101931, doi: 10.1371/journal.pone.0101931, indexed in Pubmed: 24999732.

25. Lu J, Cheng Y, Zhang G, et al. Increased expression of neuropilin 1 in melanoma progression and its prognostic significance in patients with melanoma. Mol Med Rep. 2015; 12(2): 2668-2676, doi: 10.3892/mmr.2015.3752, indexed in Pubmed: 25954957.

26. Jiang H, Xi Q, Wang F, et al. Increased expression of neuropilin 1 is associated with epithelial ovarian carcinoma. Mol Med Rep. 2015; 12(2): 2114-2120, doi: 10.3892/mmr.2015.3580, indexed in Pubmed: 25845525.

27. Shahrabi-Farahani S, Wang L, Zwaans BMM, et al. Neuropilin 1 expression correlates with differentiation status of epidermal cells and cutaneous squamous cell carcinomas. Lab Invest. 2014; 94(7): 752-765, doi: 10.1038/labinvest.2014.66, indexed in Pubmed: 24791743.

28. Beck B, Driessens G, Goossens S, et al. A vascular niche and a VEGF-Nrp1 loop regulate the initiation and stemness of skin tumours. Nature. 2011; 478(7369):399-403, doi: 10.1038/ nature10525, indexed in Pubmed: 22012397.

29. Miao HQ, Lee P, Lin H, et al. Neuropilin-1 expression by tumor cells promotes tumor angiogenesis and progression. FASEB J. 2000; 14(15): 2532-2539, doi: 10.1096/fj.000250com, indexed in Pubmed: 11099472.

30. Kawasaki T, Kitsukawa T, Bekku Y, et al. A requirement for neuropilin-1 in embryonic vessel formation. Development. 1999; 126(21): 4895-4902, indexed in Pubmed: 10518505.

31. Jones EAV, Yuan Li, Breant C, et al. Separating genetic and hemodynamic defects in neuropilin 1 knockout embryos. Development. 2008; 135(14): 2479-2488, doi: 10.1242/ /dev.014902, indexed in Pubmed: 18550715.

32. Kawakami T, Tokunaga T, Hatanaka H, et al. Neuropilin 1 and neuropilin 2 co-expression is significantly correlated with increased vascularity and poor prognosis in nonsmall cell lung carcinoma. Cancer. 2002; 95(10): 2196-2201, doi: 10.1002/ cncr.10936, indexed in Pubmed: 12412174.

33. Ben Q, Zheng J, Fei J, et al. High neuropilin 1 expression was associated with angiogenesis and poor overall survival in resected pancreatic ductal adenocarcinoma. Pancreas. 2014; 43(5): 744-749, doi: 10.1097/MPA.0000000000000117, indexed in Pubmed: 24632553.

34. Marone G, Varricchi G, Loffredo S, et al. Mast cells and basophils in inflammatory and tumor angiogenesis and lymphangiogenesis. Eur J Pharmacol. 2016; 778: 146-151, doi: 10.1016/j.ejphar.2015.03.088, indexed in Pubmed: 25941082. 
35. Kawaguchi K, Suzuki E, Nishie M, et al. Downregulation of neuropilin-1 on macrophages modulates antibody-mediated tumoricidal activity. Cancer Immunol Immunother. 2017; 66(9): 1131-1142, doi: 10.1007/s00262-017-2002-2, indexed in Pubmed: 28432397.

36. Stasikowska-Kanicka O, Wagrowska-Danilewicz M, Danilewicz $\mathrm{M}$. T cells are involved in the induction of macrophage phenotypes in oral leukoplakia and squamous cell carcinoma-a preliminary report. J Oral Pathol Med. 2018; 47(2): 136-143, doi: 10.1111/jop.12657, indexed in Pubmed: 29108105.

37. Ribatti D. Mast cells and macrophages exert beneficial and detrimental effects on tumor progression and angiogenesis. Immunol Lett. 2013; 152(2): 83-88, doi: 10.1016/j.imlet.2013.05.003, indexed in Pubmed: 23685256.
38. Stasikowska-Kanicka O, Wągrowska-Danilewicz M, Danilewicz M. Association of infiltrating cells with microvessel density in oral squamous cell carcinoma. Pol J Pathol. 2017; 68(1): 40-48, doi: 10.5114/pjp.2017.67614, indexed in Pubmed: 28547979.

39. Ji JD, Park-Min KH, Ivashkiv LB. Expression and function of semaphorin $3 \mathrm{~A}$ and its receptors in human monocyte-derived macrophages. Hum Immunol. 2009; 70(4): 211-217, doi: 10.1016/j.humimm.2009.01.026, indexed in Pubmed: 19480842.

40. Casazza A, Laoui D, Wenes M, et al. Impeding macrophage entry into hypoxic tumor areas by Sema3A/Nrp1 signaling blockade inhibits angiogenesis and restores antitumor immunity. Cancer Cell. 2013; 24(6): 695-709, doi: 10.1016/j. ccr.2013.11.007, indexed in Pubmed: 24332039.

Submitted: 19 April, 2018 Accepted after reviews: 29 May, 2018 Available as AoP: 4 June, 2018 